BNL-113342-2016-IR

File \# 94295

\title{
Micellar Surfactant Association in the Presence of a Glucoside-based Amphiphile Detected via High-Throughput Small Angle X-ray Scattering
}

\author{
Vesna Stanić, Charlotte Broadbent, Elaine DiMasi, \\ Ramiro Galleguillos and Valerie Woodward
}

Submitted to Lubrizol Research and Development Report

November 2016

Photon Sciences Department

Brookhaven National Laboratory

\author{
U.S. Department of Energy \\ USDOE Office of Science (SC), \\ Basic Energy Sciences (BES) (SC-22)
}

Notice: This manuscript has been authored by employees of Brookhaven Science Associates, LLC under Contract No. DE- SC0012704 with the U.S. Department of Energy. The publisher by accepting the manuscript for publication acknowledges that the United States Government retains a non-exclusive, paid-up, irrevocable, world-wide license to publish or reproduce the published form of this manuscript, or allow others to do so, for United States Government purposes. 


\section{DISCLAIMER}

This report was prepared as an account of work sponsored by an agency of the United States Government. Neither the United States Government nor any agency thereof, nor any of their employees, nor any of their contractors, subcontractors, or their employees, makes any warranty, express or implied, or assumes any legal liability or responsibility for the accuracy, completeness, or any third party's use or the results of such use of any information, apparatus, product, or process disclosed, or represents that its use would not infringe privately owned rights. Reference herein to any specific commercial product, process, or service by trade name, trademark, manufacturer, or otherwise, does not necessarily constitute or imply its endorsement, recommendation, or favoring by the United States Government or any agency thereof or its contractors or subcontractors. The views and opinions of authors expressed herein do not necessarily state or reflect those of the United States Government or any agency thereof. 


\section{Micellar Surfactant Association in the Presence of a Glucoside-based Amphiphile Detected via High- Throughput Small Angle X-ray Scattering}

Vesna Stanic ${ }^{*}$, Charlotte Broadbent ${ }^{2}$, Elaine DiMasi ${ }^{3}$, Ramiro Galleguillos ${ }^{4}$ and Valerie Woodward ${ }^{4}$

${ }^{1}$ Brazilian Synchrotron Light Source, Caixa Postal 6192 CEP 13083-970, Campinas, São Paulo, Brasil

${ }^{2}$ Engineering Department, Columbia University, New York NY 10027

${ }^{3}$ Photon Sciences Division, Brookhaven National Laboratory, Upton NY 11973

${ }^{4}$ Lubrizol Advanced Materials, 9911 Brecksville Road, Cleveland OH 44141

DOI No. 10.13140/RG.2.2.18010.54728

Corresponding Author LNLS: Vesna Stanić

e-mail: vesna.stanic@lnls.br

tel: $+55193512-1044$

fax: +55 19 3512-1004

Corresponding Author Lubrizol: Ramiro Galleguillos

e-mail: ramiro.galleguillos@1ubrizol.com

tel USA: 2160447-6196

Keywords: Personal care, cleansers, surfactant formulations, shampoo, bath soap, micelles, Glucamate ${ }^{\mathrm{TM}}$ CCO Thickener (MEGCCO), synchrotron, small angle x-ray scattering, high throughput analysis 
Lubrizol Research and Development Report - Monday, November 14, 2016

\section{Abstract}

The interactions of mixtures of anionic and amphoteric surfactants with sugar amphiphiles were studied via high throughput small angle x-ray scattering (SAXS). The sugar amphiphile was composed of Caprate, Caprylate, and Oleate mixed ester of methyl glucoside, MeGCCO. Optimal surfactant interactions are sought which have desirable physical properties, which must be identified in a cost effective manner that can access the large phase space of possible molecular combinations. X-ray scattering patterns obtained via high throughput SAXS can probe a combinatorial sample space and reveal the incorporation of MeGCCO into the micelles and the molecular associations between surfactant molecules. Such data make it possible to efficiently assess the effects of the new amphiphiles in the formulation. A specific finding of this study is that formulations containing comparatively monodisperse and homogeneous surfactant mixtures can be reliably tuned by addition of $\mathrm{NaCl}$, which swells the surfactant micelles with a monotonic dependence on salt concentration. In contrast, the presence of multiple different surfactants destroys clear correlations with $\mathrm{NaCl}$ concentration, even in otherwise similar series of formulations. 


\section{Introduction}

The use of natural product ingredients is currently a major trend in global cosmetics. Renewable and natural-based ingredients suitable for the formulation of cleansing products continue to be a strong need in the personal care products industry. These kinds of ingredients are added to a cleansing formulation to affect physical-chemical properties such as rheology and clarity, and to create mild products producing minimal skin and eye irritation. Cleansing surfactant compositions such as shampoos, bath gels, and liquid soaps are typically composed of anionic and zwitterionic surfactant pairs. One such pair extensively used in cleansing formulations is composed of sodium lauryl sulfate (SLS) and cocamido propyl betaine (CAPB). To improve the overall performance of this surfactant pair, we have investigated the addition of new sugar amphiphiles composed of a blend of esters of Methyl Glucose Caprate / Caprylate / Oleate, termed MeGCCO [1]. The challenge for our investigation is to quickly identify which regions of our multicomponent phase diagram are those in which the MeGCCO is incorporated with measurable effects on the rheology and other properties, most directly pertinent to the final product but time consuming and impractical to measure for a large number of formulations.

Our approach using high throughput small-angle x-ray scattering (SAXS) takes advantage of the fact that in the relevant $\mathrm{NaCl}$-stabilized aqueous solutions, these amphiphiles associate into micelles. These superstructures, which can be spherical or rod-like, further interact with each other, with tangible effects on macroscopic viscosity and optical clarity, by forming short-ranged clusters and also lyotropic liquid crystalline phases with long range order. Example structures are schematically shown in Figure 1. SAXS has been used extensively to study the morphology of pure model systems of this kind. For example, sodium lauryl ether sulfate (SLES) and CAPB were found to form long rod micelles in the presence of salt, with well-defined core-shell cylindrical shape and a measurable variation in diameter, micellar spacing, and radius of gyration with different surfactant compositions [2]. A double layered cylinder, wormlike micelle phase in SLES-CAPB had been similarly characterized as a function of salt concentration using SAXS [3]. 


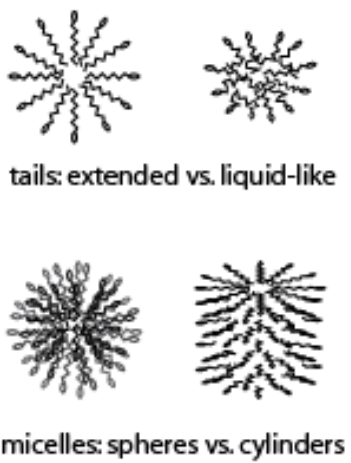

(a)

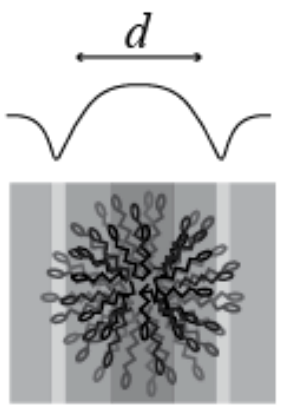

form factor

(b)

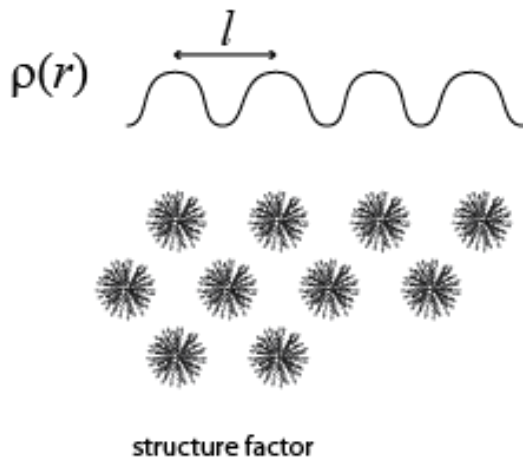

(c)

Figure 1. (a) Amphiphilic complexes assemble with hydrophobic regions collected away from the aqueous solvent, and the surfactant hydrocarbon tails may be extended (top left) or more liquid-like (top right). Micelles may be spherical (bottom left), cylindrical (bottom right), or have other shapes. (b) The form factor of the micelle is derived from subtle changes in density across the assembly, indicated by gray shading. The micelle has a characteristic length scale $d$. Shading is extended beyond the micelle to acknowledge the similar density of solvent and hydrocarbon tail regions. (c) Micelles can assemble into ordered structures with length scale $l$, with $l$ generally slightly larger than $d$. The structure factor arises from the resulting regular fluctation in density between micelle and solvent.

These studies are part of a larger body of literature that demonstrates the SAXS measurement and analysis techniques applied to surfactant systems. Examples include the effect of inorganic salts on the phase behavior of non-ionic surfactant mesophases as templates for porous ceramics [4]; presentation of the "onion" morphology of non-ionic surfactant solutions in a temperature-shear rate phase diagram [5]; and reverse micelles of non-ionic surfactants based on polyglycerol chemistry [6]. X-ray analysis is powerful, and detection of long range order is unambiguous when the ordering length scale is not close to the length scale of the particle form.

However, in micellar systems, the scattering peaks arising from the micelle forms and the micelle near-neighbor ordering are close together, and the convolution of the two presents a challenge for analysis, even for very pure and monodisperse systems [7-9]. In the commercial formulations of interest here, each named surfactant is a collection of disperse molecules. Refinement of a structure becomes impractical, as fits to numerous parameterized models must be investigated for every scattering pattern. The process is unlikely to be fruitful if automated, and not very compatible with the demands of the high throughput study. 
In this paper we present two approaches to high throughput SAXS from micelle formulations. In the first, we establish the consistency of SAXS patterns from replicate samples in the MeGCCO/SLS/CAPB system. We explore the limits of parameterization when samples are manually background-subtracted and analyzed. We will show that reliable structure parameters could be extracted but that the sample size was too small to interpolate any physical trends that were observed. In our second approach, the solvent background subtraction step is omitted and we use SAXS from a larger survey of micellar systems incorporating MeGCCO, to identify those series in which surfactant and co-surfactant interactions are shown to strongly affect molecular association and ordering.

\section{Materials and Methods}

\section{Formulations and Characterization}

Study \#1: Cocamidopropyl Betaine (Chembetaine ${ }^{\mathrm{TM}} \mathrm{CAD}^{\mathrm{TM}}$ Surfactant), Sodium Lauryl Sulfate (Sulfochem ${ }^{\mathrm{TM}}$ SLS-K Surfactant), and Methyl Glucoside Methyl Glucose Caprate / Caprylate / Oleate (Glucamate ${ }^{\mathrm{TM}} \mathrm{CCO}$ Thickener, or MegCCO) were supplied by Lubrizol Advanced Materials, Inc. Sodium chloride 100\% pure was purchased from VWR Scientific. All materials were used as received without further purification. The surfactant solutions were prepared at room temperature in demineralized water. See Table I for composition information. 
Table I. Formulations in Study \#1.

\begin{tabular}{|c|c|c|c|c|c|c|c|c|c|}
\hline $\begin{array}{c}\text { Sample } \\
\text { No. }\end{array}$ & $\begin{array}{c}\text { SLS/CAPB } \\
\text { Ratio }\end{array}$ & $\begin{array}{c}\text { Total Surf. } \\
\text { wt } \%\end{array}$ & $\begin{array}{l}\text { SLS } \\
\text { wt } \%\end{array}$ & $\begin{array}{l}\text { CAPB } \\
\text { wt } \%\end{array}$ & $\begin{array}{c}\text { MeG-CCO } \\
\text { wt } \%\end{array}$ & $\begin{array}{l}\mathrm{NaCl} \\
\text { wt \% }\end{array}$ & $\begin{array}{c}\operatorname{Visc}\left(2 \mathrm{~s}^{-1}\right) \\
\mathrm{mPa} \cdot \mathrm{s}\end{array}$ & $\begin{array}{c}\operatorname{Visc}\left(7 \mathrm{~s}^{-1}\right) \\
\mathrm{mPa} \cdot \mathrm{s}\end{array}$ & $\begin{array}{c}\text { Turbidity } \\
\text { NTU }\end{array}$ \\
\hline 1 & $10 / 4$ & 16 & 11.43 & 4.57 & 4 & 0 & $10,050.0$ & $9,775.0$ & 2.95 \\
\hline 2 & $10 / 4$ & 10 & 7.14 & 2.86 & 4 & 2 & 100.0 & 50.0 & milky \\
\hline 3 & $10 / 4$ & 10 & 7.14 & 2.86 & 0 & 0 & 10.0 & 10.0 & 1.42 \\
\hline 4 & $10 / 4$ & 16 & 11.43 & 4.57 & 0 & 0 & $2,400.0$ & $2,400.0$ & 1.69 \\
\hline 5 & $10 / 4$ & 16 & 11.43 & 4.57 & 0 & 2 & $224,000.0$ & $61,440.0$ & 3.83 \\
\hline 6 & $10 / 4$ & 16 & 11.43 & 4.57 & 4 & 0 & $10,250.0$ & $9,887.5$ & 3.09 \\
\hline 7 & $10 / 4$ & 10 & 7.14 & 2.86 & 0 & 2 & $172,800.0$ & $43,200.0$ & 4.83 \\
\hline 8 & $10 / 4$ & 10 & 7.14 & 2.86 & 4 & 0 & $9,050.0$ & $7,025.0$ & milky \\
\hline 9 & $10 / 4$ & 13 & 9.29 & 3.71 & 2 & 1 & $26,750.0$ & $10,287.5$ & 4.34 \\
\hline 10 & $10 / 4$ & 13 & 9.29 & 3.71 & 2 & 1 & $25,400.0$ & $10,337.5$ & 4.33 \\
\hline 11 & $10 / 4$ & 13 & 9.29 & 3.71 & 2 & 1 & $25,150.0$ & $10,512.5$ & 4.33 \\
\hline 12 & $10 / 4$ & 16 & 11.43 & 4.57 & 4 & 2 & 100.0 & 137.5 & 22.40 \\
\hline 13 & $10 / 4$ & 10 & 7.14 & 2.86 & 0 & 0 & 10.0 & 10.0 & 1.40 \\
\hline 14 & $10 / 4$ & 13 & 9.29 & 3.71 & 2 & 1 & $22,950.0$ & $10,237.5$ & 4.32 \\
\hline 15 & $10 / 4$ & 13 & 9.29 & 3.71 & 1 & 0.5 & $26,450.0$ & $7,950.0$ & 3.13 \\
\hline 16 & $10 / 4$ & 13 & 9.29 & 3.71 & 3 & 0.5 & $2,950.0$ & $2,950.0$ & 4.08 \\
\hline 17 & $10 / 4$ & 16 & 11.43 & 4.57 & 1 & 0.5 & $183,040.0$ & $48,320.0$ & 2.68 \\
\hline 18 & $10 / 4$ & 14 & 10 & 4.00 & 2 & 0.5 & $192,000.0$ & $50,560.0$ & 3.75 \\
\hline 19 & $10 / 4$ & 10 & 7.14 & 2.86 & 3 & 0.5 & 650.0 & 687.0 & 6.15 \\
\hline 20 & $10 / 4$ & 10 & 7.14 & 2.86 & 3 & 1 & 100.0 & 150.0 & 7.90 \\
\hline 21 & $10 / 4$ & 13 & 9.29 & 3.71 & 2 & 0 & $11,150.0$ & $6,025.0$ & 3.97 \\
\hline 22 & $10 / 4$ & 13 & 9.29 & 3.71 & 1 & 0 & 650.0 & 762.5 & 2.63 \\
\hline 23 & $10 / 4$ & 14 & 10.00 & 4.00 & 1 & 0 & $2,650.0$ & $2,675.0$ & 2.64 \\
\hline 24 & $10 / 4$ & 14 & 10.00 & 4.00 & 2 & 0 & $25,550.0$ & $7,250.0$ & 3.76 \\
\hline
\end{tabular}

The esterification synthesis method used for the Glucamate ${ }^{\mathrm{TM}} \mathrm{MeGCCO}$ has been published elsewhere [1]. Briefly, the ester is prepared by the trans-esterification reaction of Methyl Glucoside (MeG) with a mixture of the methyl esters of caprylic, capric, and oleic acids according to the simplified reaction scheme:
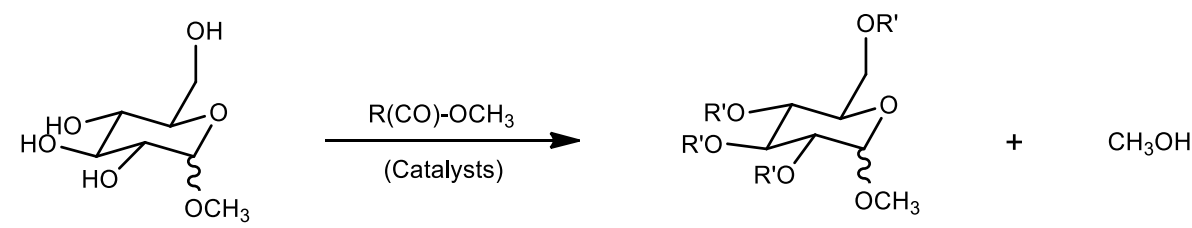

$$
\mathrm{R}^{\prime}=\mathrm{R}(\mathrm{CO}) \text { or } \mathrm{H}
$$


A conventional esterification synthesis method was used. $R$ represents the hydrocarbon portion of caprylic, capric, or oleic acids. The degree of esterification of MeGCCO was chosen to be 1.2 as determined by optimizing its performance as associative rheology modifier in surfactant cleansing formulations. The result of the synthesis is a mixture of predominantly mono-substituted methyl glucoside esters.

The degree of esterification DS was measured by $\mathrm{H}^{+}$NMR with Pyridine-D5 solvent at room temperature on a Bruker AV-500 NMR spectrometer operating at 500.13 MHz. Formulation viscosity was measured using a Brookfield®5 Viscometer, RVDV+II Pro by Brookfield Engineering, USA, SPDL SC24 at $20 \mathrm{rpm}$ and $20 \pm 0.1^{\circ} \mathrm{C}$. The turbidity of the solutions was measured using a Micro 1000 Turbidimeter by HF Scientific Inc. USA.

Study \#2 utilized further variations of SLS/CAPB/MeGCCO/NaCl as described above, plus additional surfactants as follows. High purity SLS (99\%) was purchased from Aldrich. A commercial surfactant mixture termed here as MM was supplied by Lubrizol Advanced Materials, Inc. and had the composition shown in Table II. Sodium Lauryl Ether Sulfate (SLES2EO) with two moles of ethoxylation (Sulfochem ${ }^{\mathrm{TM} E S 2)}$ ) was also supplied by Lubrizol Advanced Materials, Inc.

Table II. Composition of commercial surfactant mixture MM.

\begin{tabular}{llc}
\hline Chemical Name & Trade Name & Wt \% Active Matter \\
\hline Ethoxylated Disodium Lauryl Sulfosuccinate (DSLS) & Chemccinate $^{\mathrm{TM}}$ DSLS Surfactant & 1.0 \\
Sodium C14-C16 Olefin Sulfonate (AOS) & Sulfochem $^{\mathrm{TM}}$ AOS-K Surfactant & 5.5 \\
Cocamidopropyl Betaine (CAPB) & Chembetaine $^{\mathrm{TM}}$ CAD Surfactant & 6.2 \\
\hline Total Surfactants & & $\mathbf{1 2 . 7}$ \\
\hline
\end{tabular}

\section{High Throughput SAXS and analysis}

SAXS experiments were performed at Beamline X6B at the National Synchrotron Light Source, Brookhaven National Laboratory (see Figure SM-1 in the Supplemental Materials section.) For both studies, the incident $x$-ray energy was $16 \mathrm{keV}$ (wavelength $\lambda=0.77 \AA$ ). A scattering wave vector $q$ ranging from 0.03 to $0.43 \AA^{-1}$ was acquired using a CCD area 
detector located $163 \mathrm{~cm}$ from the sample. SAXS patterns were calibrated and integrated to obtain scattered intensity $I(q)$ curves. The $q$ calibration was performed using a silver behenate standard. The experiment used a combinatorial sample scanner capable of measuring through the wells of three standard well plates loaded at once, a total of up to 188 formulations.

Details have been published elsewhere [10]. Samples were loaded into custom 96-well plates, fabricated from Teflon at the NSLS. The plates were $2 \mathrm{~mm}$ thick, with wells $6 \mathrm{~mm}$ in diameter. Surfaces were sealed by compression with Mylar clear film on both sides and positioned vertically in the beam.

X-ray data frames acquired by the detector were named by batch and automatically numbered sequentially, and each data frame header stored the scanner position, count time, and incident and transmitted x-ray intensities as metadata. After the synchrotron run, Python scripts were used to extract metadata and associate them with scan file names, to create a "data dictionary" to which additional attributes could be readily added, and which could be exported to a new metadata file for further work. The x-ray data were merged with experimental characterization such as rheology data, using scripts that read from the laboratory spreadsheet files, into a global data dictionary. Additional scripts were written to create frame-specific batch code for data calibration, reduction, visualization, and background subtraction for fitting. Peak fitting in both studies was done manually for each frame using the programs Datasqueeze [11], Igor Pro [12], and SERENA [13].

\section{Results and Discussion}

\section{Study \#1}

Table I shows the surfactant compositions and associated characterization data for Study \#1. The compositions included various replicate samples, i.e. $1 / 6,3 / 13$, and $9 / 10 / 11 / 14$, that were prepared and studied separately.

General features of the scattering patterns are evident in the unprocessed data of Figure 2. Such images can be obtained on-line during the synchrotron experiment with no post processing. With only one exception, the Study \#1 scattering patterns are ring-shaped with a variation of the maxima (yellow) being more intense for certain formulations, for example Samples 1 and 6 in panel (a), and Sample 5 and 12 in panel (d). The ring shape proves that 
surfactant molecules aggregate into micelles. Replicates are shown offset in Figure 2, to show that these samples exhibit identical SAXS patterns. The SAXS data clearly show regions of "like" samples, especially clearly in Fig. 1(a) where Samples 21-24 in the middle of the phase diagram are almost identical, while increased surfactant concentrations along either axis create more intense $\mathrm{x}$-ray scattering, and push the SAXS pattern into a quantitatively different false-color region. Scattering is weakest for the minimum surfactant content, bottom left, Samples 3, 13.
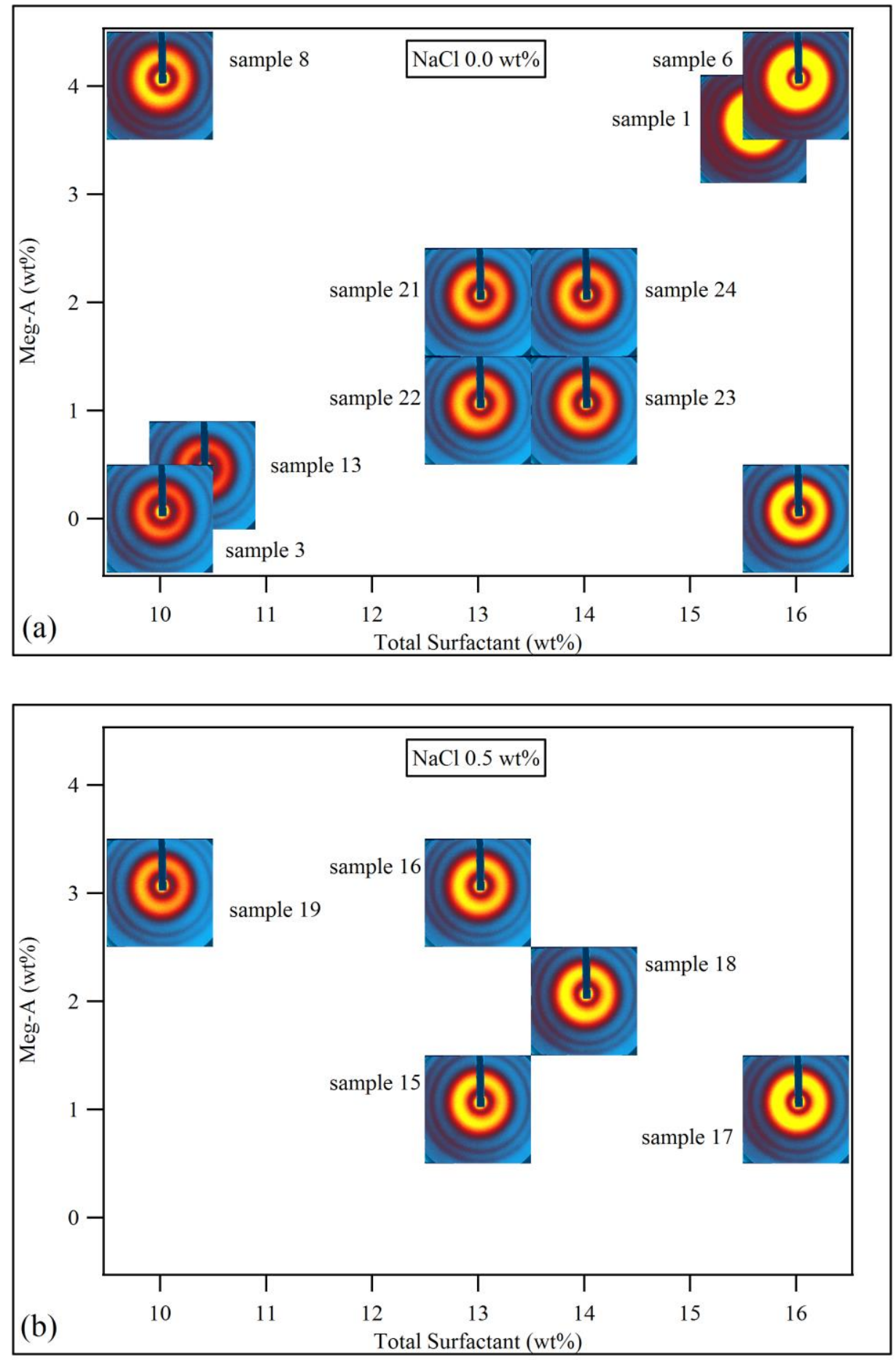
Figure 2. (Continued on next page)
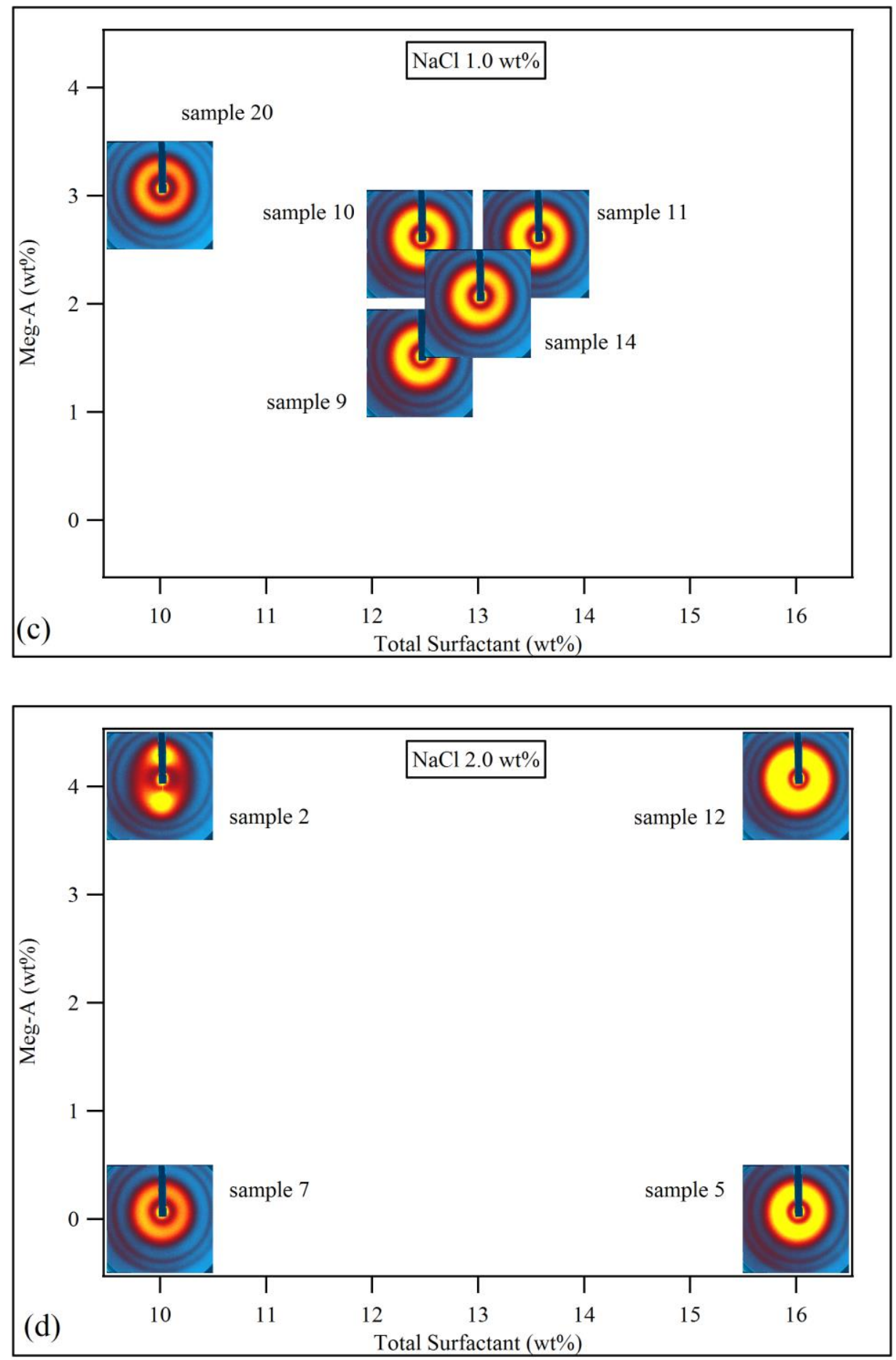

Figure 2. SAXS data in the formulation parameter space. False color SAXS intensity patterns were generated (blue=low, red=intermediate, yellow=high), on the same scale relative to the direct beam, for samples in Study \#1. Patterns are placed according to the Total Surfactant - Meg-A phase diagrams, in separate panels for each $\mathrm{NaCl}$ concentration: (a) $0.0 \mathrm{wt} \%$, (b) $0.5 \mathrm{wt} \%$, (c) $1.0 \mathrm{wt} \%$, (d) $2.0 \mathrm{wt} \%$. The center of each SAXS panel corresponds to the nominal surfactant concentrations, except for replicate samples shown underneath and offset, as follows. (a) Samples 13 and 1 are duplicates of Samples 3 and 6 (positions 10, 0 and 16, 4) respectively. (c) Samples 9, 10, 11, and 14 are replicates, at position $(13,2)$. 
Samples 21 to 24 are of special interest because they are the most comparable to the formulations that were subsequently commercialized by Lubrizol. Samples 19 and 20, towards the left in Fig. 1(b) and (c) respectively, are also in this "near-commercial formula" group. One can see that all six share a similar SAXS intensity. In the absence of salt, this characteristic is found for intermediate Total Surfactant concentrations of 13-14 wt\%. With the addition of up to $1.0 \mathrm{wt} \% \mathrm{NaCl}$, this scattering characteristic moves to the left along the Total Surfactant Axis, to values of $10 \mathrm{wt} \%$. With $13 \mathrm{wt} \%$ Total Surfactant and non-zero $\mathrm{NaCl}$, greater SAXS intensity is obtained.

The more intense SAXS patterns can arise from a number of physical mechanisms: examples might be stronger intermolecular interactions that join micelles together, or greater concentrations of molecules in assembly rather than separately dissolved. Such mechanisms could be expected to correlate with the viscosity, turbidity, and other physical characteristics important for commercial applications. To test such hypotheses, we found it necessary to treat the Study \#1 data with manual solvent background subtraction and peak fitting to $I(q)$ curves from integrated SAXS patterns. Results from Study \#1 fits will be shown without details; our discussion of Study \#2 will show the features of the $I(q)$ data.

The correlation of SAXS intensity with surfactant concentration is demonstrated in Figure 3. For each $\mathrm{NaCl}$ concentration (see color scale), the micelle form factor fit peak value has been plotted against the sum of SLS, CPAB, and Meg-CCO concentrations, showing a monotonic distribution. Note that the maximum peak amplitude for $0.0 \mathrm{wt} \% \mathrm{NaCl}$ is obtained with 20 wt $\%$ surfactant, and the same maximum peak amplitude for $1.0 \mathrm{wt} \% \mathrm{NaCl}$ is obtained with $15 \mathrm{wt} \%$ surfactant. This validates the similar information inferred without analysis from Figure 2. 


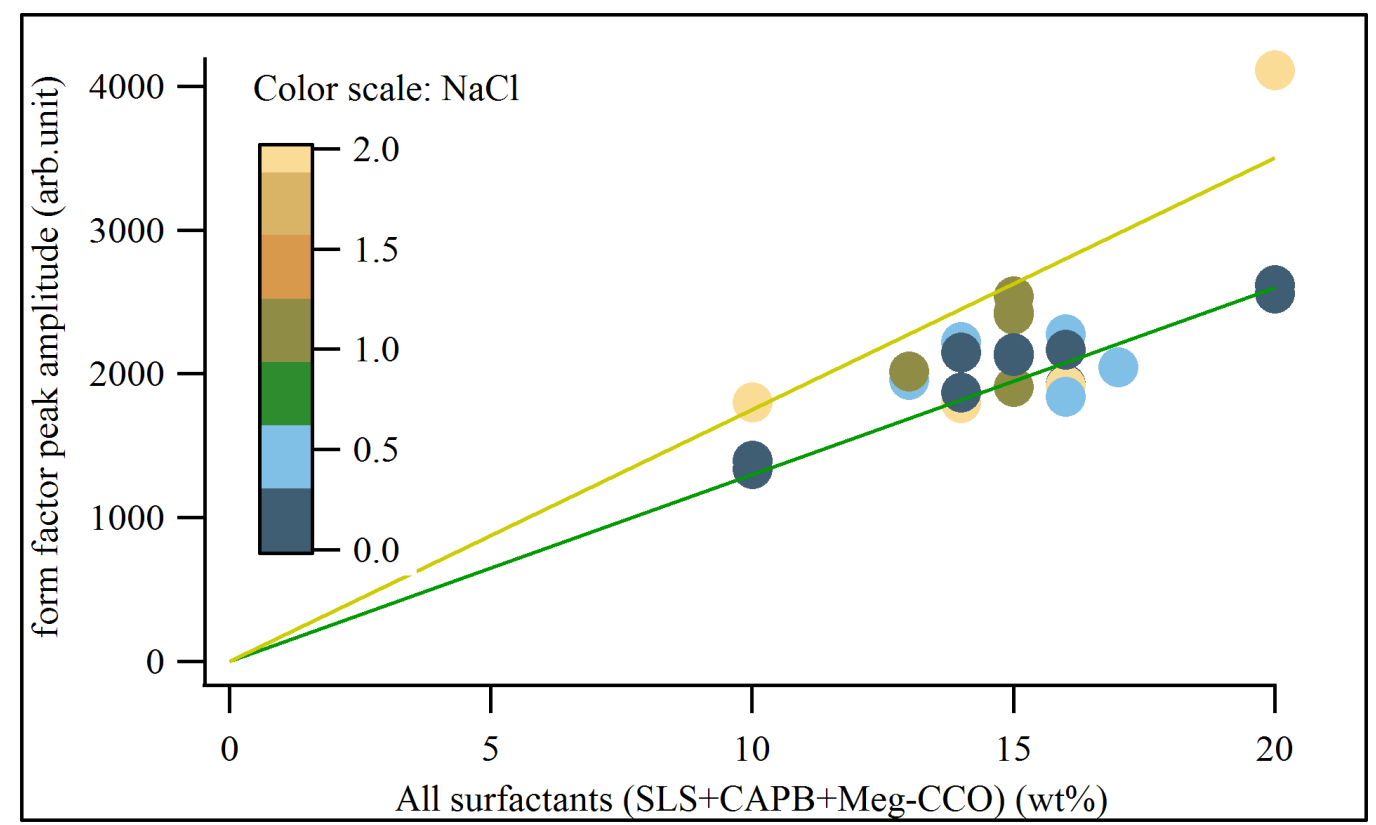

Figure 3. Form factor fit peak amplitude, corresponding to SAXS scattering intensity, as function of concentration of all surfactants, Study \#1.

Since SAXS is capable of measuring micelle size and micelle-micelle spacing, it is of interest to relate these parameters to other characteristics. As an illustration, we plot the measured turbidity and viscosity data against the micelle form factor length scale in Figure 4. We noticed that the length scale values seemed to cluster into two groups, Group 1 near $4.1 \mathrm{~nm}$ values, and Group 2 near 4.4-4.5 nm values. Turbidity values (open and closed circles) are comparable between the groups. Samples 19-24 are denoted by closed circles in the turbidity data, and belong to Group 2. Group 2 appears to have viscosity values spanning more orders of magnitude than Group 1, which exhibit only the highest viscosities. These observations do not allow any firm conclusions in this small sample set, but illustrate the potential power of high throughput scattering to quickly sort formulations into groups with qualitatively different characteristics. 


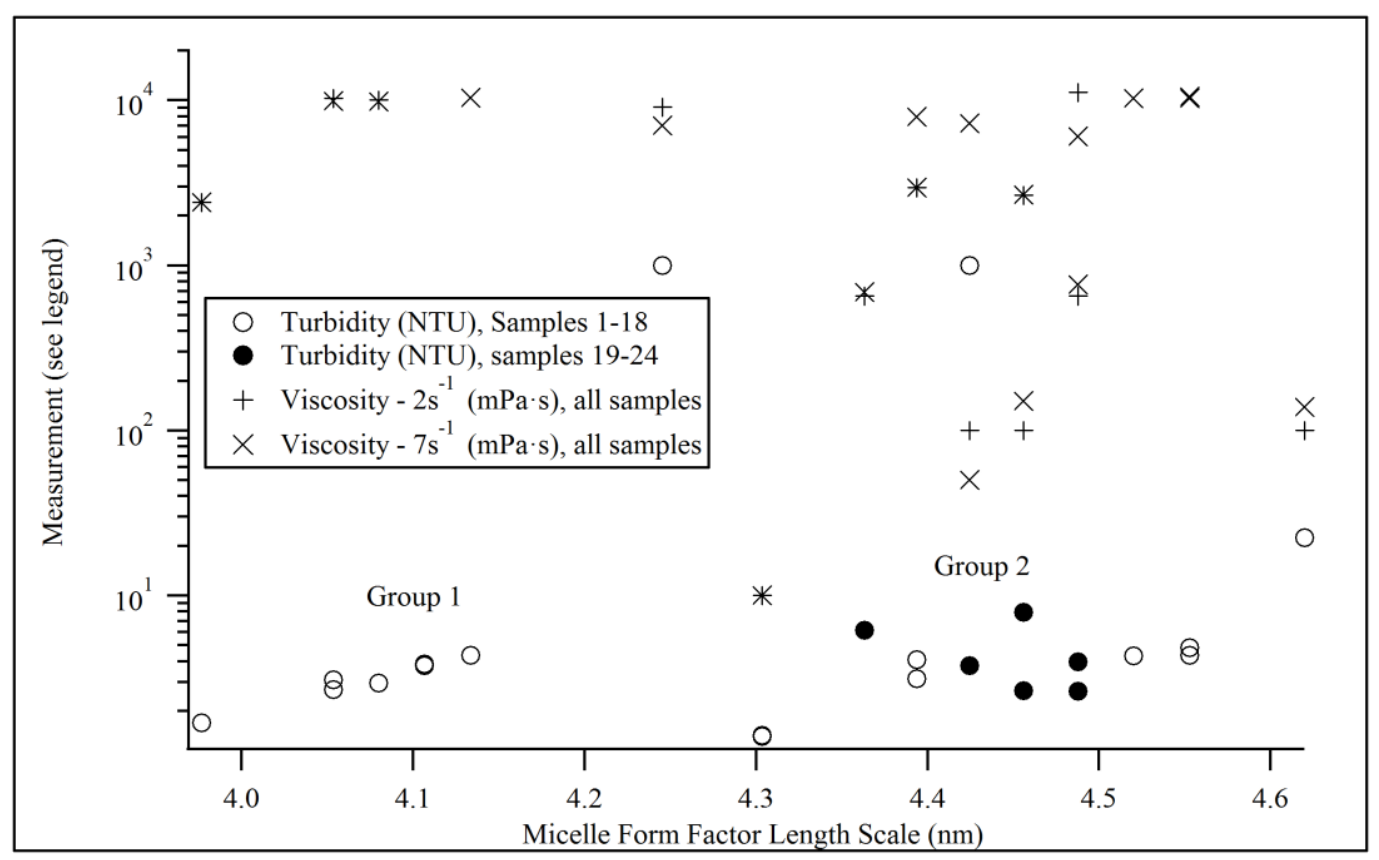

Figure 4. SAXS and physical property data in Study \#1. The micelle size indicated by form factor peak position is clusered into Group 1 near $4.1 \mathrm{~nm}$ and Group 2 near 4.4-4.5 $\mathrm{nm}$. Both groups have comparable turbidity. Group 2 has much larger variability in viscosity. Sample 19-24 are emphasized with a different marker color in the turbidity data. See also Table I.

\section{Study \#2}

We pursued several new aims with Study \#2. For increased relevance to the industrial process, we studied a greater number of formulations. Rather than restricting the surfactants to small monodisperse supplies, we studied an increasing range of variability in the surfactant sources, from larger batches of named molecules to more general mixtures. And we restricted our analysis to observations made with a minimum of data treatment. The data will be exclusively shown as integrated $I(q)$ curves, with no solvent background subtraction. These data are not suitable for reliable parameter fits but when they are plotted together, it is easy to see whether trends or variability dominate, as we will show.

Sample Group A - SLS/CAPB, MeGCCO, and NaCl sources as in Study \#1. The uniformity of these formulations with composition are evident in the $I(q)$ data of Figure 5. The intensity is dominated by the micelle form factor, with peak position approximately indicated by the vertical dashed line, corresponding to the $d$ parameter of Fig. 1(b). Within each SLS/CAPB series, MeGCCO content has little effect. The peak width assessed on the high- $q$ side appears 
to increase with greater SLS/CAPB content, an indication of greater micelle size

polydispersity. The asymmetrical peak shape also indicates the presence of a structure factor, parameter $l$ in Fig. 1(c). This appears as a shoulder near $q=0.09 \AA^{-1}$, marked in Fig. 5 with black arrows. The changes in $d$ from sample to sample are small and not systematic. By contrast, the shoulder moves leftward, to larger length scale $l$, with increase of $\mathrm{NaCl}$ from 0.0 wt\% (dotted line), through intermediate values (solid lines), to the maximum values (dashed lines). The data show that the effect of salt is to swell the liquid crystal lattice, without changing the micellar size or size distribution.

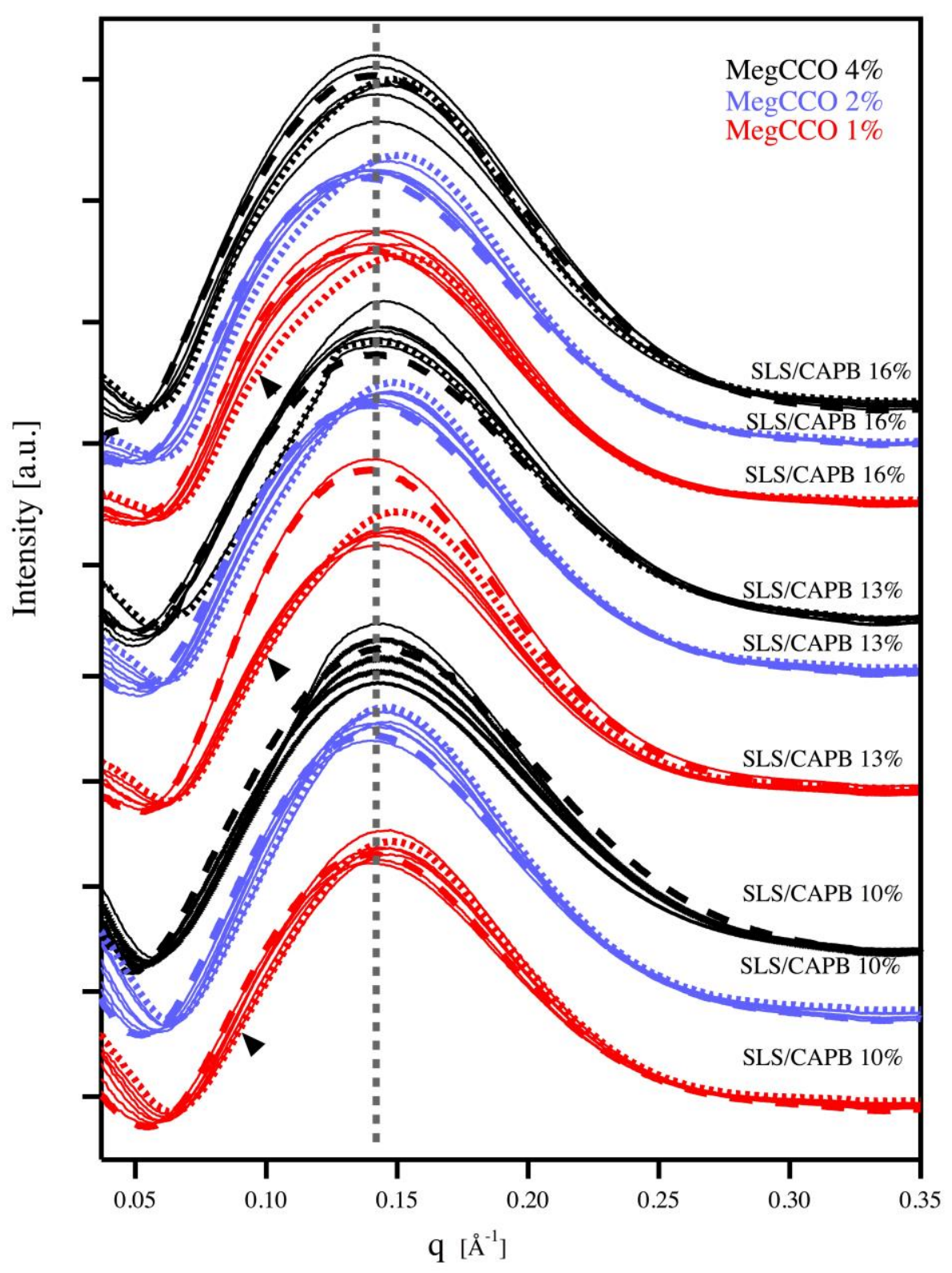


Lubrizol Research and Development Report - Monday, November 14, 2016

Figure 5. Sample Group A in Study \#2, $I(q)$ data from SAXS. Curves are offset for clarity. SLS/CABP and MegCCO content as labeled. $\mathrm{NaCl}$ content ranges from $0.25 \mathrm{wt} \%$ (dotted line) to $2.00 \mathrm{wt} \%$ (dashed line), with intermediate values (0.25 wt\% increments) shown as solid lines. See also Supporting Information, Table 1.

Sample Group B - This group includes a mixture of SLS surfactants and MeGCCO. This group seeks to identify differences in micellar formation when using the high purity (99\%) SLS from Aldrich versus the commercial grade Sulfochem ${ }^{\mathrm{TM}}$ SLS-K, without CAPB.

Omitting the CAPB from the formulations has a pronounced effect, removing the uniformity and enabling phase separation. The data of Figure 6 show additional sharp peaks due to minor phases of possibly undissolved or hydrated solid surfactant. The SLS-Sulfochem formulations may indicate similar effect of $\mathrm{NaCl}$ to swell the micelle lattice, but the SLSAldrich samples show a large shift of the form factor peak position when $\mathrm{NaCl}$ concentration changes from 2.0 to $4.0 \mathrm{wt} \%$, an effect not exhibited in the CAPB containing samples. And in these samples, MeGCCO has a pronounced effect on SAXS intensity, observed as peak height. We conclude that without CAPB, the SLS-MeGCCO is sufficiently unstable as a micellar liquid crystal to be easily perturbed from one structure to another. In addition, the evidence of undissolved material, a very clear and simple signal in SAXS, is a warning of the difficulty in controlling the surfactant composition. 


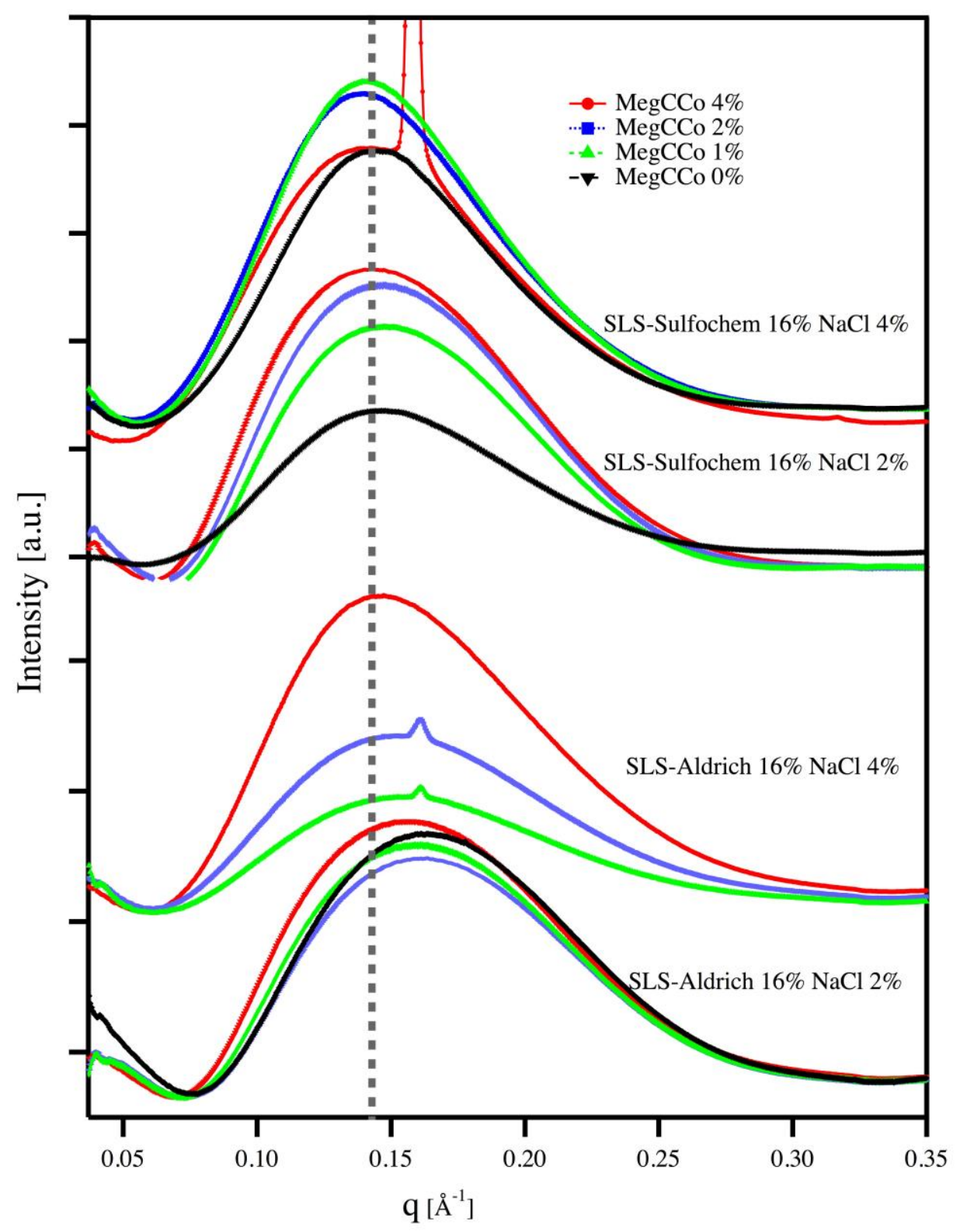

Figure 6. Sample Group B in Study \#2, $I(q)$ data from SAXS. Curves are offset for clarity. SLS, NaCl, and MeGCCO content as labeled. See also Supporting Information, Table 2.

Sample Group C - This group contains a mixture of DSLS, AOS, and CAPB surfactants, termed MM, as described above. This is a typical mixture of ionic and betaine surfactants used in many industrial cleansing compositions where the use of sulfated surfactants such as SLS is not desired due to performance or cost reasons. The SAXS data for the MM system shows multiple broad and sharp peaks, Figure 7. This means both that micelles of more than one size have stabilized in the sample, and that undissolved or hydrated surfactant material is 
present as well. It is almost certain that the differently sized micelles have within them different surfactant compositions. Within each group of curves, however, the mechanism of lattice swelling by salt is still plausible. This could mean that as long as the micelles have a certain degree of stability - which they can attain in the mixed sample due to the variety of molecules available to settle in to the structure - the ionic screening effects $\mathrm{NaCl}$ can have a predictable outcome to enlarge the spacing between micelles. It remains to correlate this more directly with a desirable physical property in the formulation.

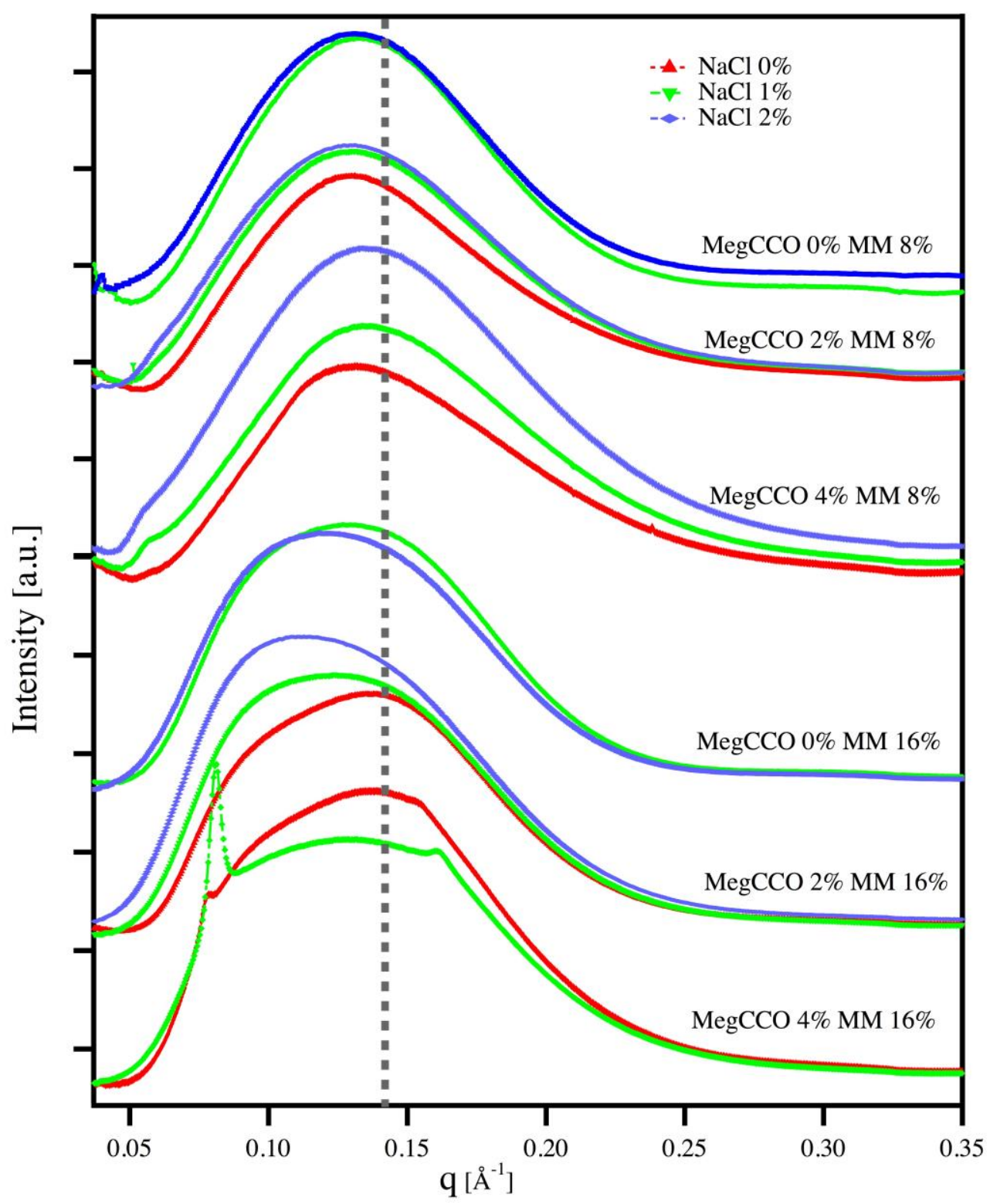

Figure 7. Sample Group C in Study \#2, I(q) data from SAXS. Curves are offset for clarity. NaCl, MeGCCO, and Total Surfactant MM content as labeled. See also Supporting Information, Table 3. 


\section{Conclusions}

The addition of sugar amphiphiles to mistures of SLS and CAPB have been studied using SAXS to establish the incorporation of the amphiphiles in the surfactant micelles. The study illustrates how high throughput SAXS, using visualizations of raw data or data with minimal analysis, can reliably distinguish between groups formulations that will be similar in composition and likely similar in certain physical characteristics. In complex amphiphile systems, the rapid surveys of phase space made possible by high throughput SAXS - a technique being increasingly done in rapid-access and mail-in-sample modes at the synchrotrons - can prove invaluable. It is not necessary to quantitatively fit structures to make use of the information provided by x-ray scattering. Increased demand by scientific and industrial communities for this technique have the added benefit of demanding more sophisticated on-line visualization tools, which can be implemented in the facilities for the benefit of future users.

A specific finding of this study is that when monodisperse surfactant formulations can form stable micelles, addition of $\mathrm{NaCl}$ in the $0.5-4.0 \mathrm{wt} \%$ range has the effect of swelling the lattice of associated micelles. When polydispersity in the surfactant formulation significantly decreases the stability of micelles, the addition of $\mathrm{NaCl}$ has unpredictable effects and can swell the micelle lattice or change the sizes of the micelles themselves.

We also highlight the lesson of Sample Group B, comparing high purity SLS to the commercial grade product. High purity SLS is an anionic surfactant with formula $\mathrm{C}_{12}-\mathrm{OSO}_{3}$, whereas commercial grade SLS can be represented by $R-\mathrm{OSO}_{3}$ where $R$ is typically a mixture of hydrocarbons ranging from $\mathrm{C}_{8}$ to $\mathrm{C}_{18}$ where the $\mathrm{C}_{12}$ hydrocarbon predominates. In practical application, production of a uniform surfactant solution is a basic requirement. Hence it is significant that in our study, in the absence of CAPB, the SAXS survey quickly reveals that the more stable and uniform structures were obtained with the commercial grade Sulfochem SLS, compared to the high purity Aldrich SLS. This points out the serious drawback in extrapolating SAXS data, as well as other interfacial characterization data, obtained from formulations using high purity SLS for application to formulations based on commercial grade SLS. 


\section{References}

1. Galleguillos R and Wu A (2013) Alkyl glycoside-based micellar thickeners for surfactant systems. Patent WO/2013/188183 USA.

2. Naruse K et al (2009) Flexibility and cross-sectional structure of an anionic dual-surfactant wormlike micelle explored with small-angle $\mathrm{x}$-ray scattering coupled with contrast variation technique. J. Phys. Chem. B 113:10222-10229

3. Eguchi K et al (2007) Salt-concentration dependence of the structure and form factors for the wormlike micelle made from a dual surfactant in aqueous solutions. J. Appl. Cryst. 40:s264-s268

4. Zheng L et al (2003) Effect of inorganic salts on the phase behavior of an aqueous mixture of heptaethylene glycol dodecyl ether. Langmuir 19:10487-10494

5. Ito M, Kosaka Y, Kawabata Y, and Kato T (2011) Transition processes from the lamellar to the onion state with increasing temperatures under shear flow in a nonionic surfactant/water system studied by Rheo-SAXS. Langmuir 27:7400-7409

6. Shrestha LK, Dulle M, Glatter O, and Aramaki K (2010) Structure of polyglycerol oleic acid ester nonionic surfactant reverse micelles in decane: growth control by headgroup size. Langmuir 26:7015-7024

7. Itri R and Amaral LQ (1991) Distance distribution function of sodium dodecyl sulfate micelles by x-ray scattering. J. Phys. Chem. 95:423-427

8. Itri R and Amaral LQ (1993) Micellar-shape anisotropy near isotropic - liquid-crystal phase transitions. Phys. Rev. E 47:2551-2557

9. Itri R and Amaral LQ (1994) Small-angle x-ray scattering of systems with inhomogenoues particles. J. Appl. Cryst. 27:20-24

10. Stanić V et al (2011) Phase diagrams of electrostatically self-assembled amphiplexes. Macromolecules 44:7423-7429

11. Heiney PA (2015) Datasqueeze (Computer Software) Version 3.0.4. www.datasqueezesoftware.com 12. Igor Pro: WaveMetrics, Inc., Lake Oswego, OR, USA. 
Lubrizol Research and Development Report - Monday, November 14, 2016

13. Micu AM and Smith JC (1995) SERENA: a program for calculating X-ray diffuse scattering intensities from molecular dynamics trajectories. Computer Physics Communications 91:331-338. 


\section{DISCLAIMERS}

\section{Lubrizol}

The information contained herein is being furnished for informational purposes only, upon the express condition that the User makes its own assessment of the appropriate use of such information. While the information contained herein is believed to be reliable, no representations, guarantees or warranties of any kind are made as to its accuracy, suitability for a particular application or the results to be obtained herefrom. Lubrizol Advanced Materials, Inc. ("Lubrizol") cannot guarantee how any products associated with this information will perform in combination with other substances or in User's process. Due to the variations in methods, conditions and equipment used commercially in processing these materials, no warranties or guarantees are made as to the suitability of the information/products for the applications disclosed. Lubrizol shall not be liable and the User assumes all risk and responsibility for, any use or handling of any material beyond Lubrizol's direct control. LUBRIZOL MAKES NO WARRANTIES, EXPRESS OR IMPLIED, INCLUDING, BUT NOT LIMITED TO, THE IMPLIED WARRANTIES OF MERCHANTABILITY OR FITNESS FOR A PARTICULAR PURPOSE. It is the User's sole responsibility to determine if there are any issues relating to patent infringement of any component or combination of components relating to the supplied information. Nothing contained herein is to be considered as permission, recommendation, nor as an inducement to practice any patented invention without the permission of the patent owner.

\section{BROOKHGUEN NATIONAL LABORATORY}

This report was prepared as an account of work sponsored by an agency of the United States Government. Neither the United States Government nor any agency thereof, nor any of their employees, nor any of their contractors, subcontractors, or their employees, makes any warranty, express or implied, or assumes any

legal liability or responsibility for the accuracy, completeness, or any third party's use or the results of such use of any information, apparatus, product, or process disclosed, or represents that its use would not infringe privately owned rights. Reference herein to any specific commercial product, process, or service by trade name, trademark, manufacturer, or otherwise, does not necessarily constitute or imply its endorsement, recommendation, or favoring by the United States Government or any agency thereof or its contractors or subcontractors. The views and opinions of authors expressed herein do not necessarily state or reflect those of the United States Government or any agency thereof.

Notice: This manuscript has been co-authored by employees of Brookhaven Science Associates, LLC under Contract No. DE-SC0012704 with the U.S. Department of Energy. The publisher by accepting the manuscript for publication acknowledges that the United States Government retains a non-exclusive, paid-up, irrevocable, world-wide license to publish or reproduce the published form of this manuscript, or allow others to do so, for United States Government purposes. 


\section{Supplemental materials:}

Table 1

Sample Group A in Study \#2. This table is supporting information for Figure 5.

\begin{tabular}{|c|c|c|c|c|c|}
\hline $\begin{array}{l}\text { SLS/CAPB } \\
\text { Ratio }\end{array}$ & $\begin{array}{l}\text { Total } \\
\text { Surf }\end{array}$ & SLS & CAPB & Meg-CCO & $\mathrm{NaCl}$ \\
\hline & wt \% & wt \% & wt \% & wt \% & wt \% \\
\hline $10 / 4$ & 16 & 11.43 & 4.57 & 4 & 0.25 \\
\hline $10 / 4$ & 16 & 11.43 & 4.57 & 4 & 0.50 \\
\hline $10 / 4$ & 16 & 11.43 & 4.57 & 4 & 0.75 \\
\hline $10 / 4$ & 16 & 11.43 & 4.57 & 4 & 1.00 \\
\hline $10 / 4$ & 16 & 11.43 & 4.57 & 4 & 1.25 \\
\hline $10 / 4$ & 16 & 11.43 & 4.57 & 4 & 1.50 \\
\hline $10 / 4$ & 16 & 11.43 & 4.57 & 4 & 1.75 \\
\hline $10 / 4$ & 16 & 11.43 & 4.57 & 4 & 2.00 \\
\hline $10 / 4$ & 16 & 11.43 & 4.57 & 2 & 0.25 \\
\hline $10 / 4$ & 16 & 11.43 & 4.57 & 2 & 0.50 \\
\hline $10 / 4$ & 16 & 11.43 & 4.57 & 2 & 0.75 \\
\hline $10 / 4$ & 16 & 11.43 & 4.57 & 2 & 1.00 \\
\hline $10 / 4$ & 16 & 11.43 & 4.57 & 2 & 1.25 \\
\hline $10 / 4$ & 16 & 11.43 & 4.57 & 2 & 1.50 \\
\hline $10 / 4$ & 16 & 11.43 & 4.57 & 2 & 1.75 \\
\hline $10 / 4$ & 16 & 11.43 & 4.57 & 2 & 2.00 \\
\hline $10 / 4$ & 16 & 11.43 & 4.57 & 1 & 0.25 \\
\hline $10 / 4$ & 16 & 11.43 & 4.57 & 1 & 0.50 \\
\hline $10 / 4$ & 16 & 11.43 & 4.57 & 1 & 0.75 \\
\hline $10 / 4$ & 16 & 11.43 & 4.57 & 1 & 1.00 \\
\hline $10 / 4$ & 16 & 11.43 & 4.57 & 1 & 1.25 \\
\hline $10 / 4$ & 16 & 11.43 & 4.57 & 1 & 1.50 \\
\hline $10 / 4$ & 16 & 11.43 & 4.57 & 1 & 1.75 \\
\hline $10 / 4$ & 16 & 11.43 & 4.57 & 1 & 2.00 \\
\hline $10 / 4$ & 13 & 9.29 & 3.71 & 4 & 0.25 \\
\hline $10 / 4$ & 13 & 9.29 & 3.71 & 4 & 0.50 \\
\hline $10 / 4$ & 13 & 9.29 & 3.71 & 4 & 0.75 \\
\hline $10 / 4$ & 13 & 9.29 & 3.71 & 4 & 1.00 \\
\hline $10 / 4$ & 13 & 9.29 & 3.71 & 4 & 1.25 \\
\hline $10 / 4$ & 13 & 9.29 & 3.71 & 4 & 1.50 \\
\hline $10 / 4$ & 13 & 9.29 & 3.71 & 4 & 1.75 \\
\hline $10 / 4$ & 13 & 9.29 & 3.71 & 4 & 2.00 \\
\hline
\end{tabular}


Lubrizol Research and Development Report - Monday, November 14, 2016

\begin{tabular}{|c|c|c|c|c|c|}
\hline $10 / 4$ & 13 & 9.29 & 3.71 & 2 & 0.25 \\
\hline $10 / 4$ & 13 & 9.29 & 3.71 & 2 & 0.50 \\
\hline \multirow[t]{2}{*}{$\begin{array}{l}\text { SLS/CAPB } \\
\text { Ratio }\end{array}$} & $\begin{array}{l}\text { Total } \\
\text { Surf }\end{array}$ & SLS & CAPB & Meg-CCO & $\mathrm{NaCl}$ \\
\hline & wt \% & wt \% & wt \% & wt \% & wt \% \\
\hline $10 / 4$ & 13 & 9.29 & 3.71 & 2 & 0.75 \\
\hline $10 / 4$ & 13 & 9.29 & 3.71 & 2 & 1.00 \\
\hline $10 / 4$ & 13 & 9.29 & 3.71 & 2 & 1.25 \\
\hline $10 / 4$ & 13 & 9.29 & 3.71 & 2 & 1.50 \\
\hline $10 / 4$ & 13 & 9.29 & 3.71 & 2 & 1.75 \\
\hline $10 / 4$ & 13 & 9.29 & 3.71 & 2 & 2.00 \\
\hline $10 / 4$ & 13 & 9.29 & 3.71 & 1 & 0.25 \\
\hline $10 / 4$ & 13 & 9.29 & 3.71 & 1 & 0.50 \\
\hline $10 / 4$ & 13 & 9.29 & 3.71 & 1 & 0.75 \\
\hline $10 / 4$ & 13 & 9.29 & 3.71 & 1 & 1.00 \\
\hline $10 / 4$ & 13 & 9.29 & 3.71 & 1 & 1.25 \\
\hline $10 / 4$ & 13 & 9.29 & 3.71 & 1 & 1.50 \\
\hline $10 / 4$ & 13 & 9.29 & 3.71 & 1 & 1.75 \\
\hline $10 / 4$ & 13 & 9.29 & 3.71 & 1 & 2.00 \\
\hline $10 / 4$ & 10 & 7.14 & 2.86 & 4 & 0.25 \\
\hline $10 / 4$ & 10 & 7.14 & 2.86 & 4 & 0.50 \\
\hline $10 / 4$ & 10 & 7.14 & 2.86 & 4 & 0.75 \\
\hline $10 / 4$ & 10 & 7.14 & 2.86 & 4 & 1.00 \\
\hline $10 / 4$ & 10 & 7.14 & 2.86 & 4 & 1.25 \\
\hline $10 / 4$ & 10 & 7.14 & 2.86 & 4 & 1.50 \\
\hline $10 / 4$ & 10 & 7.14 & 2.86 & 4 & 1.75 \\
\hline $10 / 4$ & 10 & 7.14 & 2.86 & 4 & 2.00 \\
\hline $10 / 4$ & 10 & 7.14 & 2.86 & 2 & 0.25 \\
\hline $10 / 4$ & 10 & 7.14 & 2.86 & 2 & 0.50 \\
\hline $10 / 4$ & 10 & 7.14 & 2.86 & 2 & 0.75 \\
\hline $10 / 4$ & 10 & 7.14 & 2.86 & 2 & 1.00 \\
\hline $10 / 4$ & 10 & 7.14 & 2.86 & 2 & 1.25 \\
\hline $10 / 4$ & 10 & 7.14 & 2.86 & 2 & 1.50 \\
\hline $10 / 4$ & 10 & 7.14 & 2.86 & 2 & 1.75 \\
\hline $10 / 4$ & 10 & 7.14 & 2.86 & 2 & 2.00 \\
\hline $10 / 4$ & 10 & 7.14 & 2.86 & 1 & 0.25 \\
\hline $10 / 4$ & 10 & 7.14 & 2.86 & 1 & 0.50 \\
\hline $10 / 4$ & 10 & 7.14 & 2.86 & 1 & 0.75 \\
\hline $10 / 4$ & 10 & 7.14 & 2.86 & 1 & 1.00 \\
\hline $10 / 4$ & 10 & 7.14 & 2.86 & 1 & 1.25 \\
\hline $10 / 4$ & 10 & 7.14 & 2.86 & 1 & 1.50 \\
\hline $10 / 4$ & 10 & 7.14 & 2.86 & 1 & 1.75 \\
\hline $10 / 4$ & 10 & 7.14 & 2.86 & 1 & 2.00 \\
\hline
\end{tabular}




\section{Table 2}

Sample Group B in Study \#2. This table is supporting information for Figure 6

\begin{tabular}{|c|c|c|}
\hline SLS & $\mathrm{NaCl}$ & MegCCO \\
\hline$\% w t$ & $\% w t$ & \%wt \\
\hline 16 & 4 & 4 \\
\hline 16 & 4 & 2 \\
\hline 16 & 4 & 1 \\
\hline 16 & 4 & 0 \\
\hline 16 & 2 & 4 \\
\hline 16 & 2 & 2 \\
\hline 16 & 2 & 1 \\
\hline 16 & 2 & 0 \\
\hline 16 & 4 & 4 \\
\hline 16 & 4 & 2 \\
\hline 16 & 4 & 1 \\
\hline 16 & 4 & 0 \\
\hline 16 & 2 & 4 \\
\hline 16 & 2 & 2 \\
\hline 16 & 2 & 1 \\
\hline 16 & 2 & 0 \\
\hline
\end{tabular}




\section{Table 3}

Sample Group C in Study \#2. This table is supporting information for Figure 7.

\begin{tabular}{|c|c|c|c|}
\hline $\begin{array}{c}\text { Total } \\
\text { Surf }\end{array}$ & $\begin{array}{c}\text { MeG- } \\
\text { CCO }\end{array}$ & NaCl & Water \\
\hline $\mathbf{w t} \%$ & $\mathbf{w t} \%$ & $\mathbf{w t} \%$ & $\mathbf{w t} \%$ \\
\hline $\mathbf{8 . 0 0}$ & 0.00 & 1.00 & 91.00 \\
\hline $\mathbf{8 . 0 0}$ & 0.00 & 2.00 & 90.00 \\
\hline $\mathbf{8 . 0 0}$ & 2.00 & 0.00 & 90.00 \\
\hline $\mathbf{8 . 0 0}$ & 2.00 & 1.00 & 89.00 \\
\hline $\mathbf{8 . 0 0}$ & 2.00 & 2.00 & 88.00 \\
\hline $\mathbf{8 . 0 0}$ & 4.00 & 0.00 & 88.00 \\
\hline $\mathbf{8 . 0 0}$ & 4.00 & 1.00 & 87.00 \\
\hline $\mathbf{8 . 0 0}$ & 4.00 & 2.00 & 86.00 \\
\hline $\mathbf{1 6 . 0 0}$ & 0.00 & 1.00 & 83.00 \\
\hline $\mathbf{1 6 . 0 0}$ & 0.00 & 2.00 & 82.00 \\
\hline $\mathbf{1 6 . 0 0}$ & 2.00 & 0.00 & 82.00 \\
\hline $\mathbf{1 6 . 0 0}$ & 2.00 & 1.00 & 81.00 \\
\hline $\mathbf{1 6 . 0 0}$ & 2.00 & 2.00 & 80.00 \\
\hline $\mathbf{1 6 . 0 0}$ & 4.00 & 0.00 & 80.00 \\
\hline $\mathbf{1 6 . 0 0}$ & 4.00 & 1.00 & 79.00 \\
\hline
\end{tabular}




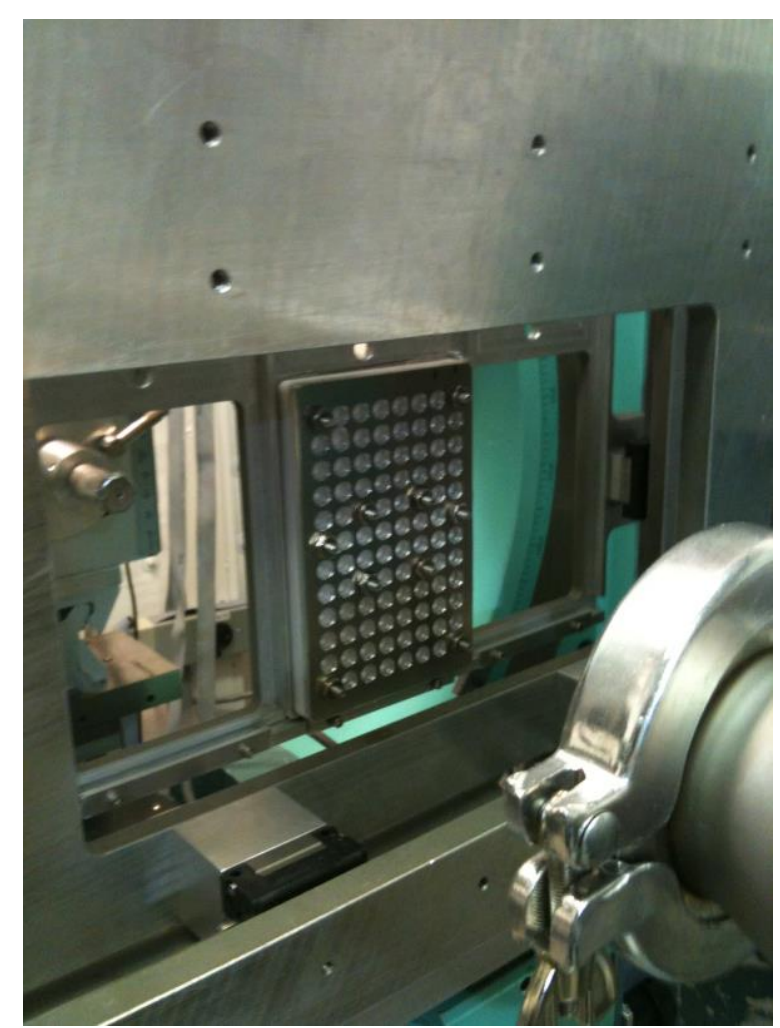

A

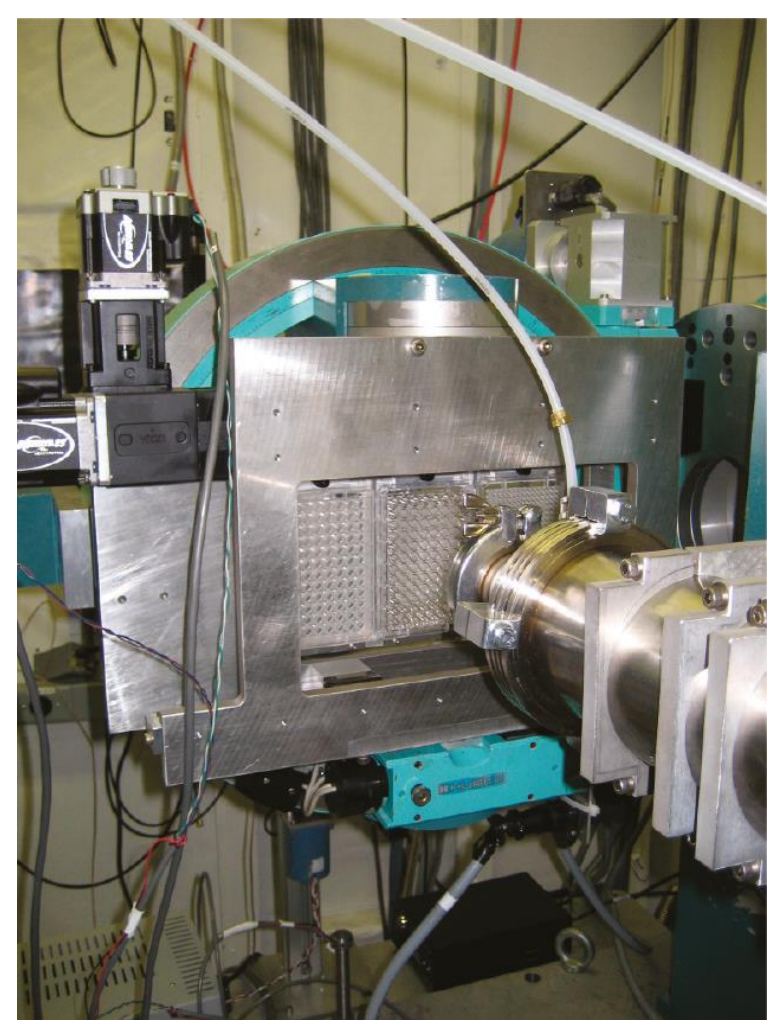

B

Figure SM-1 - A) One well plate scanner is shown mounted at the beamline. B) Several plates mounted at the beam for combinatorial work. Beam is incident on the well plates from behind, and the transmitted and scattered intensities enter the vacuum flight path in the foreground of the photo, to be measured by a photodiode beam stop and an area detector, respectively. 